\title{
Sorry Used by L2 Adult Learner: Managing Learning Opportunity and Interpersonal Relationship in Classroom Interaction
}

\author{
Ruowei Yang ${ }^{1} \&$ Xing Zhang ${ }^{2}$ \\ ${ }^{1}$ School of Education and Language, Open University of Hong Kong, HKSAR \\ ${ }^{2}$ College of Foreign Studies, Jinan University, Guangzhou, China \\ Correspondence: Xing Zhang, College of Foreign Studies, Jinan University, Guangzhou, China. E-mail: \\ maggiezhang@jnu.edu.cn
}

$\begin{aligned} & \text { Received: November 3, } 2017 \quad \text { Accepted: December 12, } 2017 \quad \text { Online Published: December 23, } 2017 \\ & \text { doi:10.5539/ijel.v8n2p48 }\end{aligned} \quad$ URL: http://doi.org/10.5539/ijel.v8n2p48

\begin{abstract}
This study investigates functions of sorry in L2 Chinese classroom interactions through the conversation analysis approach with an aim to investigate the relationship between sorry and L2 learning and possible functions of sorry in managing interpersonal relationships in classroom interactions. Through analysis of 36 hours' video-recorded classroom interaction, this research shows that the non-apologetic sorry could be employed by adult learners to obtain various learning opportunities, such as active participation, production of appropriate responses, active use of target language, and attempts to solve problems that are not designed in the teaching agenda. Moreover, sorry could be used as a strategy for constructing polite co-operation and to mitigate possible offenses against tutors during classroom interactions, as well as to manage interpersonal relationships based upon the theoretical framework of politeness. Findings from this study can also help us understand how sorry serves pragmatic purposes for L2 classroom interaction and provide us with pedagogical implications for L2 learning and teaching. Future studies need to examine sorry as used by L2 learners in conversational turns other than the same turn, as well as at different positions of a turn, to provide evidence for its functions in classroom interaction.
\end{abstract}

Keywords: sorry, conversation analysis, L2 learning opportunity, interpersonal relationship, politeness principle

\section{Introduction}

This article discusses various management functions of sorry when it is not used in the sense of apology among participants in L2 classroom interactions. The intrinsic sense of sorry as a term of apology is for "claiming personal responsibility for repair-related trouble" (Robinson, 2004). Sorry could be considered a process of grammaticalization (see Hopper \& Traugott, 2003) or a process of semantic change whereby lexical items lose their propositional meaning over time and take on grammatical, discoursal or pragmatic meaning. Previous research has made attempts to investigate how sorry has been used by L2 adult learners to perform a learning oriented organizational function, such as signaling to check understanding, correcting errors, searching for words, acknowledging a mistake or potential misunderstanding, disagreement, or new or important information. On the other hand, sorry could also serve a few organizational needs of the conversation, such as turn-taking, holding or passing the floor, utterance closing, or a shift in topic. Thus, such uses of sorry reveal how learners negotiate meaning and define their own roles as novices in the L2 learning classroom. Sorry could occur when learners have trouble in performance, especially in pronouncing L2 language items in the right tones. Sometimes, sorry could be used alone or with specific requirements such as "could you repeat?" to invite help from the tutor as the learner could have had trouble understanding or hearing the content during the previous turn. All these features demonstrate that in language-based foreign language classrooms, the correct content should be the focus of both learners and tutors.

Notwithstanding its apologetic functions, sorry is also widely recognized to accomplish non-apology actions, such as condolences or other-initiated repair (e.g., Robinson, 2004; Rhys, 2013). The non-apology actions of sorry in our data are frequently used as a signal for self-repair in classroom interaction, one of the open-class practices of repair initiation (Drew, 1997). Additionally, Robinson stated that such apology-based other-initiation of repair "communicates a stance" that repair-initiators instead of their addressees should claim responsibility due to their own hearing or understanding trouble (2006). Therefore, this study proposes that sorry used in the 
L2 classroom has a two-fold function: one is an effort made to obtain L2 learning opportunities, and the other is a strategy related to face-work or politeness, particularly towards a tutor whose face could be damaged by the offensive response of the learner.

\section{Literature Review}

\subsection{Study of Sorry}

Sorry is commonly used to express apology, but in real conversations, it is recognized by many studies to have non-apology actions (Drew, 1997; Robinson, 2004, 2006; Rhys, 2013). What is worthy of noting is that sorry is often used by learners in their interaction with tutors or fellow learners in the L2 classroom. Such an observation could suggest that the "shortcoming lies with the recipient" as opposed to suggesting a pardon (Hayashi et al., 2013). In terms of its relation to the source of trouble, Rhys (2013) notes that sorry as a self-repair initiation identified the source of trouble, i.e., the problem connected to the instance at the earlier turn, but did not repair it. Robinson (2004) examines the sequential organization of sorry-based units and their different implications for the organization of apologizing as an action. It is observed that turns in which apology units initiate a sequence of action would accomplish apology as the primary action but also non-apology, such as condolences and other-initiated repair. In some cases, they noted that sorry, always with upward intonation, can be used as other-initiated repair and comprise the entirety of the first part of an adjacency-pair sequence. In special circumstances, i.e., in aphasic conversations, the functions of sorry are noted to be far different from apology when an aphasic speaker was observed to use sorry to close down collaborative word searching, apart from moving the conversation forward, as he displayed his non-competence arising from aphasia with his difficulties in lexical choice (Rhys, 2013). Their research concluded that even sorry is indexed to regret due to its linguistic capacity, and its apology function is subordinate to its word-search closing function.

\subsection{CA for Learning Opportunities}

An increasing number of researchers on CA (Conversation Analysis) classroom interaction (such as Ellis, 2012; Johnson, 1996; Ohta, 2001; Rivers, 1987; Waring, 2008) have attempted to address the relationship between interaction and learning. Rivers (1987) states that interaction is very important to enhance students' language competence as they can apply their knowledge of the language they have learned to live conversation through a few processes, such as listening to authentic linguistic material or the output of their fellow students in discussions, and participating in joint problem-solving tasks.

The CA framework is considered to be a fine-grained methodology widely used in the area of SLA as it focuses on interactional practices to comprehensively understand the processes of L2 learning. In a talk-in-interaction, each participant's own perspective will be examined along with their changing identities as expert or novice (e.g., Hall, 2010; Macbeth, 2004; Waring, 2009). To be specific, CA-driven research tends to look closely at the sequential development of speakers' collaborative efforts to manage problems occurring in interactions, which is believed to be a more complicated method than the IRF (Initiation-Response-Feedback) model (Seo, 2015). Additionally, regarding objects of language acquisition study, there has been a shift away from abstract linguistic items to various interactional practices exploiting "participants' co-construction and orientation to social order", e.g., turn construction or turn taking (Hellermann, 2009, p. 231). As one of these interactional practices that draw researchers' attention most, conversational repair is defined as a mechanism used to address trouble in speaking, hearing, or understanding (Schegloff, Jefferson, \& Sacks, 1977).

As for the specific patterns of communication in second language acquisition classrooms, Johnson (1996) notes that in most classrooms, active participation by learners could enhance their learning. Even if active participation is not explicitly taught, it could be implicitly enforced through teachers' use of language. Ellis (2012) argues that as repairs could make problems explicit and result in solutions, they can afford potential learning opportunities. Allwright (2005) discusses the contribution of teaching points to the utilization of learning opportunities from an observation that leaners could actually learn much more than the sum of teaching points. This phenomenon suggests that teaching points are not only inefficient but also counterproductive as leaners may have learned little from these teaching points but "a lot from everything else that occurred in the lesson" (p. 14). With regard to how learning occurs in conversation, Waring (2011) states that language learning occurs when the language uses of the students continue to expand. Through "actively seeking and contributing to understandings" of different issues (p. 215), they gain access to various learning opportunities, which could be considered as asserting "ownership of their own learning process" (p. 215). Furthermore, to further understand in what specific ways learner initiatives promote learning, she proposes that learner agency could generate learning opportunities through initiatives taken by learners, such as asking questions or making comments, as reflected by their extended participation in the language classroom. 
Since the introduction of the concept of scaffolding by Wood, Bruner, \& Ross (1976), an increasing number of educators have used it to describe and explain the role that teachers can play in guiding children's learning and development in teacher-student interactions (Ellis, 2012; Ohta, 2011; Waring, 2008; Verenikina, 2008; Wood, Bruner \& Ross, 1976;). Their work focuses on the process by which one speaker, be it an expert or a novice, provides assistance to another speaker (usually a novice) to grasp a skill that they are unable to perform independently. Ohta (2001) focuses on how the IRF routine in the classroom helps L2 learners to develop the interactional competence involved in producing appropriate listener responses. In particular, Verenikina (2008) believes that the application of scaffolding could provide young learners with cultural tools, thus enabling them to become independent learners, and could be used by educators in a creative and informal way. Specifically, Ellis (2012) posits the view that if scaffolding could be tuned to suit learners' developmental level, i.e., neither too much or too little, it would provide effective assistance to learner's learning.

\subsection{Studies on Expressions for Face-Work or Politeness}

Interpersonal communication among participants in social and classroom dialogues is essential to maintain participants' public face, i.e., their self-image. Politeness has been studied in various areas of linguistics, particularly sociolinguistics and pragmatics (Eelen, 2001). Brown and Levinson's politeness theory (1987) is widely cited and considers apologies "negative politeness strategies" to mitigate imposition or interruption, so they are face-saving for the hearer and face-threatening for the speaker.

Apologies have been the focus of much research on linguistic politeness (Holmes, 1995; Leech, 1983; Olshtain, 1983; Márquez-Reiter, 2000; Wagner, 2004). Leech (1983) states that the performance of apologies is to maintain harmony between the hearer and speaker because it is beneficial for the hearer, while it has a cost for the speaker; it is face-saving for the hearer and face-threatening for the speaker. According to Márquez-Reiter (2000), the speech act of an apology is mainly a kind of redressive action for the purpose of redressing face-threatening behavior to acknowledge the addressee's need "not be imposed upon and/or offended" (p. 45). Márquez-Reiter (2000) compares Uruguayan speakers of Spanish with British English speakers to investigate cross-cultural differences in terms of the use of apologies. This study suggests that even when an apology is employed when a speaker commits damaging actions towards other person, speakers of British English give more explanations when apologizing because the British English speakers attach a greater importance to saving face.

Utilizing the face-saving model in Brown \& Levinson's theory (1978), Wagner's (2004) research discusses naturally occurring apologies in Cuernavaca Spanish for the purpose of investigating the apology strategies that are most frequently used and those types of positive and negative politeness strategies used in association with the apology speech act. Among Wagner's conclusions is that speakers of the Cuernavaca speech community preferred negative-politeness markers, which contradicts observations in previous research on Spanish speaking populations. Olshtain (1983) also applies Brown and Levinson's framework to compare apology and politeness in offensive situations in different cultures. Contrary to the common view that apologies are negative politeness strategies, the author argues that in performing remedial apologies, positive face plays a central role as they are used to restore and maintain relationships on the basis of mutual interest shared in each other's needs, which is considered the essential aspect of positive politeness.

This brief literature review provides a summary of findings on the relationship between sorry and language learning, as well as studies on apologies as expressions of face-work or politeness. However, what special pragmatic functions sorry performs in the context of the L2 classroom and how its non-apology sense adopted in the same interaction could facilitate language learning remain questions worthy of exploring.

\section{Methodology}

The database comprises 36 hours of video-recordings, which were automatically achieved by the Online Learning System (OLE) when real-time e-tutorial sessions have been given during the period of the course Basic Chinese for Non-Chinese Speakers was conducted at a university in Hong Kong. In total, 66 cases of same-turn sorry used by the learners are generated. The three tutors who held e-tutorial sessions individually are native Chinese speakers with a first degree in English. The learners are all adults aged 21 to 50. The first languages of most of the learners are English. While some learners have other mother tongues, all of them have a high proficiency in English. All the learners have little to no experience learning Chinese before enrolling in the program. All video recordings are transcribed following CA transcription conventions (Hutchby \& Wooffitt, 2008; Jefferson, 2004). 


\section{Research Questions}

The study investigates non-apology functions of sorry in L2 Chinese classroom interaction from the perspectives of CA and L2 learning. Specifically, it attempts to answer the following questions:

1). What functions can sorry realize in L2 learners' utterances in classroom interaction?

2). What is the relationship between sorry when uttered by the learner and that in L2 learning?

3). What is the function of sorry when uttered by the learner in terms of managing interpersonal relationships in classroom interactions?

\section{Analysis}

All data have been processed initially by identifying all cases where sorry is uttered by students. A collection of 66 cases are extracted by applying this criterion. Afterwards, the CA approach in the form line-by-line analysis conducted for each case is taken, with special attention devoted to the context of the use of sorry and what functions it accomplishes. After transcription, the following six excerpts are analyzed following the qualitative "single-episode analysis" approach (Schegloff, 1987).

\section{Excerpt 1}

1) S1: is to sell?

is (it) to sell?

2) $\mathrm{T}: \mathrm{so}$...

3) S2: mai (3) dongxi. Mai (4) dongxi.

so...
4) S1: sorry, mai (3) is to buy, and mai- ai (4) is to sell?

buy things, sell things.

sorry, buy is to buy, and sell-ll is to sell?

5) $\mathrm{T}: \quad$ yeah, yeah.

yeah, yeah.

In this interaction, the two students (S1 and S2) and the tutor (T) are discussing the meaning and usage of two action verbs in Chinese, mai (3) (to buy) and mai (4) (to sell). S1 is not sure about them as these two verbs only differ in tones in Chinese; after S2 uses the two words in a sentence (line 3), S1 uses sorry to signal that he is somewhat confused by the words and would like to get confirmation from the tutor on his understanding of the differences between these two verbs (line 4). Consequently, the tutor responds that his tentative understanding is correct. Thus, this instance of sorry used by S1 first obtains the floor for him to ask questions to facilitate his processing of this semantic knowledge; second, it demonstrates S1's politeness towards two hearers in this conversation, i.e., S2 and the tutor, given his interruption of the ongoing interaction and his personal responsibility for mitigating the possibility of imposing on the tutor. On the other hand, in this case, the student takes initiative (Waring, 2011) through raising questions towards the enhancement of L2 learning.

\section{Excerpt 2}

1) $\mathrm{T}$ : yes, the original meaning of xie is some,

2) here means what kind of songs do

yes, the original meaning of some is some,

3) you like to listen to?

4) S: so xie is some, sorry, I don't

here means what kind of songs do

5) understand that.

you like to listen to?

so some is some, sorry, I don't

understand that.

6) T: yes, sorry, yes.

yes, sorry, yes.

7) xie means some (but here...)

some means some (but here...)

The tutor and the student are discussing the meanings of the Chinese word xie in a new context. As the student has learned xie in the sense of 'some' previously, he could not understand a difference sense of 'kind' used in a different context, according to the explanation already provided by the tutor in line 1 . The student says sorry (line 4) before specifically stating his difficulty in understanding this sense of xie. Sorry used here shows the student's expectation of the tutor to give more illustration. Thus, sorry can be considered as an indicator of the need for help. The student is then given further discussion in addressing various meanings of the word in following turns of the tutor (e.g., lines $6 \&$ 7). Before the student expresses 'I don't understand' as a request for the tutor's further clarification on this topic, he uses sorry to mitigate this imposition on the tutor. As a result, while the student is using sorry as a face-saving strategy to show his politeness to the tutor, he gets the tutor's 
help in learning the two different senses of this Chinese word. As seen here, the student makes an attempt to gain access to knowledge beyond what the tutor has designed in the teaching agenda, which can be seen as active participation that can contribute to the understanding of elements in addition to pre-assigned points.

\section{Excerpt 3}

1) S: shi. wo shi...wo shi mei (2) guo ren.

yes, I am...I am American.

2) $\mathrm{T}$ : ni zai meiguo zhu nali?

where do you live in America?

3) S: wo zhu nali...er no, sorry.

I live where...er.no, sorry,

4) wo zhu zai kēntaji.

I live in Kentucky.

5) ni de jia zai nali.

where is your hometown?

6) $\mathrm{T}$ : wo de jia zai xianggang

my hometown is hong kong.

7) ni qu guo xianggang ma?

have you been to hong kong before?

In Excerpt 3, the student and tutor are discussing the topic of hometowns. After the tutor asks the student about where his home is in the United States (line 2), the student partially repeats the tutor's question first (line 3); then, he pauses shortly with an interjection of er no when he realizes that the response he just makes to the tutor's question is wrong. The student uses sorry (line 3) to show that he is aware of his mistake and would like to correct it by himself. The instance of sorry has two functions here, one serves as an initiation for self-repair, which gives the student an opportunity to repair his utterance. This self-repair enables the student to express his thoughts in an accurate way in the L2 language, which reflects the effectiveness of self-repair. In addition, the other function of sorry in this situation is to indicate that the student takes responsibility for the mistake in his utterance before asking for help from the tutor who should be responsible for correcting his mistake in learning the language. Thus, sorry here could hold the floor for the student to produce a corrected utterance before moving the conversation forward.

\section{Excerpt 4}
1) $\mathrm{T}$ :
ni qing. ni qing.
after you, after you.
2) $\mathrm{S}: \quad \rightarrow$ sorry? what?
sorry? what?
3) $\mathrm{T}$ :
you please.
you please.
4) $\mathrm{S}$ :
oh, oh. you first? :::
oh, oh. you first? :::

In the above excerpt, sorry occurs at the beginning of the student's utterance, together with a specific initiation, what, intended to ask for more explanation about the previous utterance by the tutor, who used a common expression in L2, Ni qing (after you), to let the learner start their exercise first. Being unfamiliar with this expression, the student asked the tutor to explain it further by the use of sorry because he could not understand the tutor's utterance at all at the previous turn. The reason is that $N i$ qing is a vernacular expression, which generally is not used in writing, is used to show extreme politeness; moreover, it is not an intended language point in this course, so the student fails to understand the implication of this expression. As a result, the student uses sorry to request explanation through which he could learn an authentic expression out of this genuine conversation, as reflected by his tentative understanding of this expression in line 4 .

Therefore, this is a case in which the language uses of the student continue to expand as the language points get implicitly enforced instead of explicitly taught. As a result, the student can use the knowledge he has absorbed to later express their meaning in real life exchanges.

\section{Excerpt 5}

1) $\mathrm{T}$ : Gelin xiansheng. Ni pingshi zaoshang

2) shenme shihou qichuang ne?

3) S: $\rightarrow$ wo:::wo:::oh, sorry.

4) $\mathrm{T}: \mathrm{it}$ 's ok

5) S: $\quad$ wo::: liu dian(3) shong

\author{
Mr. Green, when do you get up \\ usually? \\ $I: \because I: \because$ Oh, sorry. \\ it's ok \\ I::: six o'clock (get up)
}

In Excerpt 5, the tutor is asking the student a question about when he usually gets up. The student fails to give a complete answer in L2, so he utters sorry at the end of his current utterance to pass the floor to the tutor (line 3), 
as he could not finish his sentences. He hesitates by repeating wo, the subject of the sentence, twice, followed by $o h$, the injection, to indicate his difficulty. Therefore, sorry here could be considered a signal by the student to end his own unsuccessful attempt to answer the question raised by the tutor at the previous turn. Nevertheless, after the tutor gives him encouragement to make another attempt, he successfully answers this question with the acceptable time adverbial used to answer this question regarding time, even though there is still a pause between the subject $w o$ and the time adverbial. In that case, the student uses sorry to obtain an opportunity to reform his answer to the tutor's question, which is a process of internalizing this knowledge. In the meantime, he shows politeness through claiming his personal responsibility for troubles caused by reattempting to answer the same question.

\section{Excerpt 6}

1) $\mathrm{T}:$

2)

3)

4) S1:

5) $\mathrm{T}$ :

6) S2: $\rightarrow$ sorry, say it again, and...

7) S1: yes, yes, you model read it.

8) because yours is better than mine.

ah, gai xiansheng, can you make a model reading for zhong xiaojie, please?

yes, yes.

can you read it properly? ah, $M r$. Guy (student 2), can you make a

model reading for Miss Jones (student 1),

please?

yes, yes.

haha!

sorry, say it again, and...

yes, yes, you model read it.

because yours is better than mine.

can you read it properly?

In Excerpt 6, the tutor and two students are reading some sentences, and the tutor plans to ask student 2 to read some words first as a model for student 1 , but student 2 does not understand the tutor's instruction, so he utters sorry to ask for repetition of the trouble source (line 6). As student 1 has understood the tutor, she explains it to leaner 2. Sorry here occurs in conjunction with the specific initiation "say it again" at the beginning of this student's utterance as the potentially difficult language point for him is the phrase model reading, which the student may not be familiar with. In addition, student 1's rephrase of this sentence is the explanation needed by student 2. Because of this, the adoption of sorry here gives an opportunity for leaner 2 to experience the application of this phrase in real conversation. That is, the output of their fellow students in joint tasks can help them increase their language store (Rivers, 1987). Meanwhile, sorry is used to accept responsibility for damage to the tutor by requesting that he repeats the instruction as the tutor's face is threatened. Correspondingly, by attempting to avoid imposition from the student, the risk of face-threat to the tutor is reduced.

\section{Conclusion}

Drawn from authentic data from online tutorials designed for adult learners, this study examines different functions of the apology-based term, sorry, in language-based classrooms using the methodology of conversational analysis. Our findings suggest that sorry can perform a dual function in interaction between learners and tutors in L2 classrooms. For L2 adult learners, sorry is used as a strategy to obtain opportunities for their L2 learning during classroom interaction; and at the same time, it could be adopted to claim personal responsibility for troubles caused during the learning process.

One major function is to construct co-operative interaction to claim personal responsibility for troubles to avoid offense against tutors during the process of L2 teaching and learning. Specifically, sorry could be used as a signal for some conversational actions, such as self-repair initiation, turn taking, floor holding or giving, utterance closing, revising previous utterances made by the students, requesting other's clarification or explanation and so on. In other words, the functions of sorry depend on the context and organizational and learning needs. Furthermore, in such classroom interactions, the attempt to uphold the politeness principle by the students is a reflection of their efforts to maintain cooperative interaction between the tutors and themselves. For instance, sorry could be used as a face-saving strategy to demonstrate a student's politeness aimed at mitigating an imposition on the tutor when there is an interruption in their interaction, a misunderstanding, or reattempts to answer some question more than once.

The second major function of sorry in the second language acquisition classroom is reflected in the fact that there are different ways to access various learning opportunities. To begin with, active participation by students, such as raising questions, making comments, or producing appropriate responses could facilitate language learning. In addition, when some language elements are implicitly enforced through teachers' and students' use 
of language, language uses of these students continue to expand. Furthermore, students can attempt to solve problems outside of the teaching agenda. At other times, the process of being immersed in the output of fellow students, in addition to reading authentic linguistic material, can promote learning. All these learning processes could be enhanced by active attempts to understanding various issues, so they can apply absorbed knowledge to express their meaning when participating in real conversation later.

On a final note, the implications of this study lie in its pedagogical significance. It indicates that the use of a popular English apologetic term in a L2 classroom, such as Chinese could facilitate L2 learning in language learning classrooms, which can contribute to our teaching of L2 to adult learners.

\section{Acknowledgments}

The work described in this paper was fully supported by a grant from the Research Grants Council of the Hong Kong Special Administrative Region, China (UGC/FDS16/H15/14).

*This research was initiated when the correspondence author worked in Open University of Hong Kong, and the current paper was finished while this author is working in Jinan University.

\section{References}

Allwright, D. (2005). From teaching points to learning opportunities and beyond. Tesol Quarterly, 39(1), 9-31. https://doi.org/10.2307/3588450

Cohen, A. D., \& Olshtain, E. (1981). Developing a measure of sociocultural competence: The case of apology. Language Learning, 31(1), 113-134. https://doi.org/10.1111/j.1467-1770.1981.tb01375.x

Drew, P. (1997). "Open” class repair initiators in response to sequential sources of troubles in conversation. Journal of Pragmatics, 28(1), 69-101. https://doi.org/10.1016/S0378-2166(97)89759-7

Ellis, R. (2012). Language teaching research and language pedagogy. New York: John Wiley \& Sons. https://doi.org/10.1002/9781118271643

Hall, J. K. (2010). Interaction as method and result of language learning. Language Teaching, 43(2), 202-215. https://doi.org/10.1017/S0261444809005722

Hellermann, J. (2009). Looking for evidence of language learning in practices for repair: A case study of self-initiated self-repair by an adult learner of English. Scandinavian Journal of Educational Research, 53(2), 113-132. https://doi.org/10.1080/00313830902757550

Holmes, J. (2013). Women, men and politeness. London, New York: Routledge.

Hopper, P. J., \& Traugott, E. C. (2003). Grammaticalization. Cambridge: Cambridge University Press. https://doi.org/10.1017/CBO9781139165525

Hutchby, I., \& Wooffitt, R. (2008). Conversation analysis. Polity.

Johnson, K. E. (1995). Understanding communication in second language classrooms. Cambridge: Cambridge University Press.

Leech, G. (1983). Principles of pragmatics (Longman linguistics library). London: Longman.

Macbeth, D. (2004). The relevance of repair for classroom correction. Language in Society, 33(5), 703-736. https://doi.org/10.1017/S0047404504045038

Ohta, A. S. (2001). Second language acquisition processes in the classroom: Learning Japanese. London, New York: Routledge.

Reiter, R. M. (2000). Linguistic politeness in Britain and Uruguay: A contrastive study of requests and apologies (Vol. 83). Amsterdam: John Benjamins Publishing. https://doi.org/10.1075/pbns.83

Rhys, C. S. (2013). Choosing not to repair: Sorry as a warrant for interactional progress. Research on Language \& Social Interaction, 46(1), 84-103. https://doi.org/10.1080/08351813.2012.726887

Robinson, J. D. (2006). Managing trouble responsibility and relationships during conversational repair. Communication Monographs, 73(2), 137-161. https://doi.org/10.1080/03637750600581206

Schegloff, E. A. (1987). Analyzing single episodes of interaction: An exercise in conversation analysis. Social Psychology Quarterly, 101-114. https://doi.org/10.2307/2786745

Schegloff, E. A., Jefferson, G., \& Sacks, H. (1977). The preference for self-correction in the organization of repair in conversation. Language, 361-382. https://doi.org/10.1353/lan.1977.0041 
Verenikina, I. (2008). Scaffolding and learning: Its role in nurturing new learners. In P. Kell, W. Vialle, D. Konza, \& G. Vogl (Eds.), Learning and the learner: exploring learning for new times (p. 236). University of Wollongong.

Wagner, L. C. (2004). Positive-and negative-politeness strategies: Apologizing in the speech community of Cuernavaca, Mexico. Intercultural Communication Studies, 13, 19-28.

Waring, H. Z. (2011). Learner initiatives and learning opportunities in the language classroom. Classroom Discourse, 2(2), 201-218. https://doi.org/10.1080/19463014.2011.614053

Wilga M. R. (Ed.). (1987). Interactive language teaching. Cambridge: Cambridge University Press.

Wood, D., Bruner, J. S., \& Ross, G. (1976). The role of tutoring in problem solving. Journal of Child Psychology and Psychiatry, 17(2), 89-100. https://doi.org/10.1111/j.1469-7610.1976.tb00381.x

\section{Appendix}

\section{Transcription Notations}

S Student

S1 Student 1

S2 Student 2

$\mathrm{T} \quad$ Tutor

I Translated words from Chinese

B keywords under discussion

[] overlapping talk

(a) laughter

(3) level of pitch out of 5, with 1 being lowest and 5 being highest. Series of numbers indicated change in pitch within a word.

$::: \quad$ stuttering or non-fluent speech

pauses or intervals

\section{Copyrights}

Copyright for this article is retained by the author(s), with first publication rights granted to the journal.

This is an open-access article distributed under the terms and conditions of the Creative Commons Attribution license (http://creativecommons.org/licenses/by/4.0/). 